Revista Iberoamericana, Vol. LXIX, Núm. 205, Octubre-Diciembre 2003, 1001-1015

\title{
LOS LÍMITES DE LA CARNE: \\ LOS CUERPOS ASEDIADOS DE VIRGILIO PIÑERA
}

\author{
POR \\ Dara E. Goldman \\ University of Illinois-Urbana
}

Se ha descrito como el caso que dividió al mundo del arte estadounidense: el cadáver de Ana Mendieta es descubierto en el techo de una tienda al lado de su apartamento en Manhattan. Su esposo, Carl Andre -considerado como el padre del minimalismo- es acusado como el asesino. La trágica ironía de este caso captura la atención del público. Junto a la contundente combinación de elementos como el asesinato, el misterio y la repentina exteriorización de chismes que normalmente se restringen a los trasbastidores de las galerías de Soho, la fascinación del público se puede atribuir a la extraordinaria representación de drama primordial que provee el caso. Como parte de las múltiples narraciones resultantes, Mendieta y Andre se convierten en caricaturas estereotipadas del género sexuado. A ella comúnmente se le describe como emocionalmente inestable, una artista afligida, torturada por un compañero autoritario e insensible. Por otro lado, esta versión contradice la representación de Andre como el esposo afligido, quien es injustamente victimizado por las sospechas generadas por el suicidio de su esposa.

El caso también se lee como si formara parte de una antología de teoría feminista. A la luz del escándalo Andre y Mendieta se contraponen como el maestro de la hegemonía patriarcal y la modelo por excelencia de la imagen del subalterno, respectivamente. Como parte de la inauguración de sus galerías nuevas, el museo Solomon R. Guggenheim auspició una muestra de arte del siglo xx. Cuando se anunció que una de las esculturas de Andre ocupaba un lugar prominente en dicha exposición, el evento recibió grandes críticas. Un grupo de manifestantes se reunió frente al lugar con carteles que decían: "Carl Andre is in the Guggenheim. ¿Dónde está Ana Mendieta?” La pregunta cuestiona, sin duda, la relativa posicionalidad de Mendieta y Andre con respecto al canon artístico. El bilingüismo y el uso del español para articular este cuestionamiento, además, denota la subalternidad de la posición de Mendieta. Ella queda marginada no únicamente como mujer y artista, sino que también está localizada -no tan solo racial y étnicamente- sino discursivamente fuera del espacio hegemónico que Andre supuestamente ocupa.

Más aún, el incidente enfatiza la exclusividad sistemática del espacio hegemónico. La normatividad de las exhibiciones en un museo requiere la exclusión del otro. Esta exclusividad y sus descontentos concomitantes crean, por otra parte, un espacio subalterno fuera de los límites del museo. Es decir, la eliminación de Mendieta por parte de Andre, como se da a entender, provoca un mayor interés crítico-paradójicamente-en su obra. En 
su performance, “Better Yet When Dead”, Coco Fusco examina la veneración póstuma hacia Mendieta como una demarcación de los valores artísticos:

Fusco's motionless embodiment reenacted Mendieta's artistic practice, but here her body of work was significantly represented as a dead one, on which mud dried and cracked unevenly. The performance, which also referred to the notorious circumstances surrounding Mendieta's death, implicated the culture of the art market and a long history of one-sided, unproblematized appropriations . (Hernández 63)

En un artículo sobre el juicio y sus consecuencias, Judd Tully observa el efecto que, a fin de cuentas, éste tuvo en la recepción de Mendieta: "The life of sculptor and performance artist Mendieta, who [...] was portrayed at the trial as marginal in the art world, has gained a much wider audience, and her career has blossomed a thousand-fold" (17). De esta manera, los eventos aparentemente crearon un espacio alternativo para la producción artística contra-hegemónica.

Las lecturas e interpretaciones de su muerte -y, por extensión, de su obra por medio de su muerte- se vuelven aún más significativas cuando se considera la naturaleza de la obra de esta artista. Las piezas de Mendieta no solían ser obras artísticas tradicionales sino que estaban a medio camino entre el performance y la escultura. Presentaba, por ejemplo, representaciones de su propio cuerpo o de otra figura femenina mezclado con la naturaleza. Aunque se conservan imágenes de sus obras en fotografías, Mendieta insistía consistentemente en crear obras efímeras, representaciones del cuerpo femenino que estarían inevitablemente vinculadas con un momento temporal y un lugar en el espacio sin poder reproducirse del todo. De esta manera, las circunstancias de su muerte adquieren una ironía macabra. Además, y de mayor importancia aún, se podría discutir que el espacio de los manifestantes sería el lugar más apropiado para su obra: se situaba fuera de los parámetros tradicionales, pero dialogando continuamente con éstos, y engendraba así un espacio artístico alternativo por y para la obra en cuestión.

Quisiera proponer aquí que se puede hallar un movimento homólogo en (y sobre) la obra del escritor cubano, Virgilio Piñera. Debido a su política personal y su posición como figura pública, quedó marginado tras la Revolución Cubana como individuo y como autor. Más aún, la marginalidad y el desplazamiento constituyen temas fundacionales dentro de su poética. Al igual que en la obra de Mendieta, y a pesar de las diferencias importantes que existen entre los medios artísticos, la representación del cuerpo figura como tema prevalente en los textos de Piñera. Los cuerpos de Piñera, además, son sometidos a procesos de constante $-\mathrm{y}$ a veces creciente- asedio. Como argumentaremos aquí, es mediante la repetida representación de cuerpos asediados que se vislumbra la posicionalidad de la voz poética piñeriana.

Desde la mitad del siglo xx, Piñera ha sido una figura reconocida en Cuba y los estudios literarios cubanos. No obstante, su obra literaria ha estado recibiendo mayor atención crítica desde la década pasada. En su análisis de la literatura gay en Cuba, por ejemplo, Emilio Bejel subraya la creciente visibilidad de las obras del autor y del discurso crítico que se ha producido acerca de ésta. La mayoría de estos enfoques críticos se centran en su relación con la Revolución Cubana, su participación en revistas literarias o su 
sexualidad, examinan la gama de complejidades en la obra de Piñera -y, en muchas ocasiones, de su vida también- y construyen una visión sobre-expansiva del sistema poético del autor. Sin embargo, la obra de Piñera demuestra ser alarmante y provocadoramente elusiva y contra-hegemónica. Como bien plantea Ana García Chichester, los escritos que Piñera produjo a lo largo de su vida apoyan y refutan, paradójicamente, cualquier análisis monolítico de sus textos. De hecho, como argüiremos, la poética de Piñera es una poética de resistencia. Hasta cierto punto su obra puede interpretarse a través de una hermenéutica múltiple y contradictoria porque continuamente cuestiona y rechaza la validez de sistemas totalitarios o hegemónicos. Sin embargo, esta resistencia no impide la posibilidad de un análisis cuidadoso o del recelo de tendencias significativas dentro de la obra del autor. Un análisis minucioso de la obra de Piñera revela varios temas centrales, incluyendo una constante insistencia en la corporalidad y la posición como características determinantes de la subjetividad.

La recepción crítica de la obra de Piñera constituye un caso de cambios extremadamente típico en el canon y que son -no obstante-altamente significativos. El autor y su obra han sido reconocidos y grandemente respetados desde que comenzó a participar en revistas literarias en Cuba. No obstante, la visibilidad de Piñera y su obra había sido limitada, hasta recientemente, a un público relativamente especializado con una que otra oleada en el ámbito popular. Sin embargo, hoy se observa un incremento constante en la importancia de obras por y sobre el autor. Por otra parte, lo más significativo de este cambio es que no se puede atribuir fácilmente a una posición política o ideológica unificada sino que abarca varios aspectos. Por lo tanto, no es fácil responder a interrogantes como "por qué Piñera y por qué ahora” analizando su atractivo dentro de un determinado grupo o programa de valores. El alcance de su atractivo se debe explicar en términos de una multiplicidad dentro de su obra.

Cualquiera que sea el enfoque, es difícil discutir la obra de Piñera sin evocar aspectos de su vida. Esta dificultad no es sorprendente dada su importancia como figura histórica y literaria. Piñera tuvo una relación compleja y polémica con la Revolución Cubana; publicó varias obras -ya sea con su nombre o con el seudónimo de "El Escriba"-en donde abogaba por cambios significativos en la política y la sociedad cubanas. Estuvo muy involucrado con las revistas Orígenes y Ciclón y su relación -textual y a veces personalcon otros escritores asociados a las revistas es también muy conocida. Particularmente la polémica implícita entre Piñera y José Lezama Lima ha sido tan discutida que en ocasiones se ha convertido en el tema principal de la crítica sobre ambos autores. ${ }^{1}$ De hecho, la política y las interacciones del autor con sus colegas literarios constituyen, frecuentemente, el enfoque principal de la crítica sobre Piñera.

Recientemente la sexualidad de Piñera se ha convertido en un tema central de estudios. La película “Mauvaise conduite”, de Nestor Almendros y Orlando Jiménez Leal, y otras obras sobre el tema, han documentado cómo Piñera -al igual que varios de sus colegas- sufrieron persecución y ostracismo en vida a causa de su sexualidad. En "The Death of Virgilio”, Cabrera Infante cuenta una infame anécdota en la que la obra de Piñera

\footnotetext{
${ }^{1}$ Entre varios estudios que se centran en la relación entre los dos autores, se destaca -por ejemploel análisis que presenta Guillermo Cabrera Infante en Mea Cuba.
} 
sufre también un trato similar: cuando Ernesto "Che” Guevara encuentra una copia del Teatro completo de Piñera en los anaqueles de la embajada cubana en Argel lanza el ejemplar contra la pared y le riñe al embajador por incluir la obra de ese "sucio maricón" en la colección de la embajada (13). ${ }^{2}$ No obstante, esta tendencia de unir al autor y su obra no se limita a sus perseguidores. La extraordinaria predominación de un enfoque biográfico dentro de la crítica contemporánea sobre Piñera sugiere que la obra del autor está destinada a ser leída constantemente en clave con su vida.

Esta aproximación biográfica a menudo engendra significativos problemas de interpretación. Una de las mayores dificultades que los críticos encuentran cuando examinan la escritura de Piñera en estos términos es la complejidad de la vida del autor. Es decir, su vida misma presenta contradicciones sustanciales y no ofrece una matriz estable desde la cual uno pueda comenzar a comprender su producción literaria. Más importante aún, quizás su escritura evita una y otra vez una fácil identificación con una posición reconocible. En su análisis, José Quiroga examina esta complejidad y argumenta que la trascendencia de Piñera como autor homosexual yace en una codificación perpetuamente elusiva que se encuentra dentro de la propia escritura. De hecho, en su capítulo sobre el escritor cubano, Quiroga subraya la compleja dificultad de interpretar su obra en términos de una poética homosexual:

But Piñera's work not only speaks in code: it likes and seduces code, and it encodes its own interventions. To rupture the complexity I have deployed in this essay for the sake of a politcs of outing does not do justice to the particularities of the work itself: it neutralizes Piñera and confines him to a space that Piñera himself could not have forseen [...] (Tropics of Desire 121)

Quiroga intenta evitar lecturas forzosas y limitantes de la obra del escritor y examina más bien el código que construye. No obstante, como bien plantea Quiroga, la interpretación de dicho código tiende a apuntar a lecturas biográficas que encierran el texto en un sistema de interpretación políticamente (sobre)determinada. Asimismo, paradójicamente, los silencios resultan tan elusivos como las articulaciones y apuntan a las insuficiencias reductivas del marco interpretativo homosexual (al igual que el homofóbico). Por ende, llevado a sus últimas consecuencias, el sistema poético que construye Piñera resiste la totalidad de las normas hegemónicas no sólo políticas, sino también textuales. Cuestiona fundamentalmente los límites ideológicos de cualquier sistema de significación y de esta manera construye una posicionalidad radicalmente contra-hegemónica y -en todo sentido de la frase- un espacio queer.

Aunque muchos críticos han abordado la representación de las islas y la geografía insular en la obra de Piñera, este aspecto no ha sido el enfoque principal en la mayoría de los casos (Quiroga, “On the Weight”, West). Por lo tanto, las múltiples manifestaciones de los tropos insulares y sus implicaciones a través de la oeuvre del autor aún no han sido analizadas a fondo. Un análisis cuidadoso de este aspecto es significativo cada vez más

2 “The Death of Virgilio” se publicó como introducción a la antología Cold Tales, la cual es una traducción de Cuentos fríos y otras historias no incluidas en la edición original en español. 
dado su rol en la literatura de Piñera: esta representación, a menudo contradictoria, de los tropos insulares en su obra refleja una problemática fundamental dentro de su poética.

Uno de sus primeros poemas, "La isla en peso” (1943), constituye una de las más obvias manifestaciones de insularidad en la escritura de Piñera. El poema representa una crisis ante la cual la respuesta primaria es un lamento. Se expresan varios aspectos de la crisis y, la fuente fundamental que supuestamente los engendra es una oposición irreconciliable. Cada aspecto consta de una oposición binaria, una dicotomía en la que las categorías divididas se amenazan una a la otra en vez de complementarse o facilitar una síntesis beneficiosa para ambas.

La primera de estas dicotomías es la separación de la tierra y el agua. El poema comienza con una descripción de la circunstancia insular y su efecto:

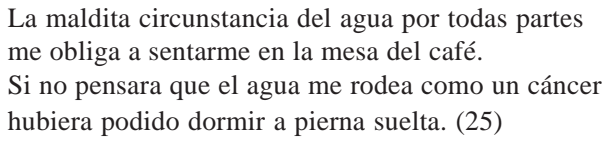

La frontera entre el mar y la tierra no es tan solo un tema sobresaliente en el poema: de manera consistente Piñera presenta esta frontera como problemática y disruptiva. A través del poema el agua y el mar son caracterizados como una limitación, una amenaza capaz de destruir a la isla y sus habitantes.

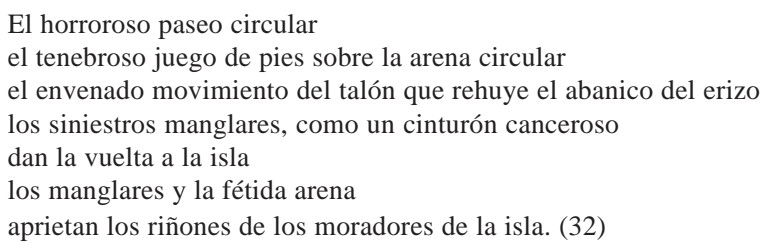

Dada esta constante amenaza, la isla debe protegerse a sí misma de la invasión de estos elementos destructivos. Sin embargo, Piñera da respuestas contradictorias a la situación. En repetidas ocasiones, el poema establece el deseo de obtener una división más completa entre la tierra y el agua por medio de una creciente separación. Pero, a veces, las imágenes sugieren que la separación misma es el problema y que ambos elementos deben estar fundidos o combinados para poder superar el problema de la dicotomía presente.

No obstante, este conflicto no se limita a la oposición del mar y la tierra; el poema incluye respuestas similarmente contradictorias a las otras dicotomías que establece. En varias ocasiones el poema construye una clara distinción entre la isla y el mundo más allá de ésta. Por un lado, esta distinción caracteriza a la isla como relativamente subdesarrollada y carente, y por lo tanto, sugiere que ésta debe superar sus propias limitaciones a través de la expansión de sus confines. Por ejemplo, el poema implica que al isleño le falta la habilidad de comprender los procesos de cambio global: "todas esas historias, leídas por un isleño que no sabe lo que es un cosmos resuelto” (38). Más aún, la putativa ignorancia de los lectores es especialmente problemática dada la presencia de una historiografía 
alternativa en el poema. En una sección, una historia reconstruida de la isla es presentada como una potencial fuerza de resolución. Por lo tanto, aún si este conflicto sobre la naturaleza insular pudiera ser contra-atacado a través de la escritura de tal historia, el impacto de esta solución presumiblemente podría ser reducido por la limitada capacidad interpretativa de los lectores -una limitación que nace, a punto, por su aislamiento. Por otra parte, el poema presenta el relativo aislamiento de la isla como potencialmente ventajoso: "afortunadamente desconocemos la voluptuosidad y la caricia francesa" (29). ${ }^{3}$

Más allá de las específicas circunstancias de insularidad, la dinámica de las oposiciones binarias en "La isla en peso" se extiende a otros elementos externos e internos. Es decir, la dicotomía dinámica determinada por los atributos físicos de la isla circunscribe y a la vez define la existencia insular: se hace contraste entre plantas y animales autóctonos y extranjeros, así como entre el negro y el blanco, la luz y la oscuridad, el pasado y el presente. En cada caso, el poema enfatiza, tanto la necesidad de resolver el conflicto que dicha oposición crea, como la necesidad de mantener tal separación ya que los elementos yuxtapuestos son capaces de destruirse entre sí. La llegada de la luz, por ejemplo, se representa como una violenta invasión:

Pero la claridad avanzada, invade

perversamente, oblicuamente, perpendicularmente,

la claridad es una enorme ventosa que chupa la sombra,

y las manos van lentamente hacia los ojos. (36)

El problema, sin embargo, no es ni la claridad ni la oscuridad por sí mismas. La fuerza destructiva emana de un proceso transitorio en donde un estado de iluminación es continuamente interrumpido por el próximo: "los cuatro momentos en que se abre el cáncer: madrugada, mediodía, crepúsculo y noche” (33).

De esta manera, Piñera presenta una serie de dicotomías volátiles que se parecen a su tratamiento de las condiciones físicas de la insularidad, un paralelo que Piñera refuerza a través del uso de la metáfora. En varias ocasiones los elementos naturales son caracterizados como cuerpos u órganos corporales. Dentro de este sistema simbólico humano y natural los elementos interaccionan directamente: "El trópico salta y su chorro invade mi cabeza/ pegada duramente contra la costra de la noche” (30). El autor no sólo usa metáforas corporales a través del poema, sino que el límite -como con la yuxtaposición de otros elementos físicos- se convierte en el punto focal dentro de sus imágenes corporales. Por ejemplo, la cabeza golpea contra la corteza o la costra de la noche. De manera similar, la piel y los orificios corporales se convierten en el lugar de negociación entre lo externo y lo interno: “Confusamente un pueblo escapa de su propia piel.../la piel, en esta hora, se extiende como un arrecife/y muerde su propia limitación” (35). De este modo, la isla y su contenido se representan como un cuerpo individual. Además, el poema vuelve a enfatizar el rol de la piel: es la piel la que define a este cuerpo colectivo y su posible transformación.

\footnotetext{
${ }^{3}$ Cabe decir que este pasaje en "La isla" se ha interpretado como una crítica al estilo barroco de Lezama. Pero, aún si aceptamos esta interpretación, la crítica de Piñera a Lezama se basa en una incorporación inapropiada de elementos extranjeros.
} 
El efecto acumulativo de estos elementos crea un sistema basado en el contraste entre oposiciones de elementos internos y externos. La existencia insular, en el poema, es determinada por este conflicto. Además, las dinámicas establecidas dentro de este contexto indican que la existencia requiere del cuidado constante de este delicado balance entre los elementos opuestos.

"La isla en peso" también sugiere que la escritura misma es engendrada por la dinámica insular de los opuestos binarios. En cierta ocasión -como mencionamos anteriormente- se postula la posibilidad de reconstruir la historia. Por otra parte, la propuesta re-escritura de la historia isleña ofrece la posibilidad de recuperar elementos perdidos y, por lo tanto, mejorar la situación presente.

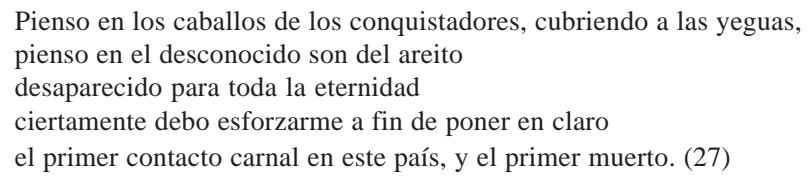

Es el propio acto de escritura el que establece la necesaria relación entre los elementos insulares. De hecho, a menudo la solución propuesta a los conflictos dicotómicos es la inscripción de una construcción alternativa: "Yo combino" (30). Es decir, el poeta identifica el conflicto y lucha para alcanzar el balance necesario entre los elementos opuestos.

En “La isla”, Piñera construye un sistema en donde tanto la identidad nacional como su sistema poético están determinados por una dinámica de insularidad. En otras obras del autor no se vislumbra tan explícitamente el tema de la insularidad geográfica. No obstante, estas obras se centran en la misma problemática de la yuxtaposición dicotómica entre elementos internos y externos analizados en el poema anterior. De esta manera, los tropos que se vinculan con una vida insular en la poesía de Piñera se convierten en los temas predominantes de su prosa.

En la colección, Cuentos fríos, Piñera desarrolla su poética de la paradoja dicotómica en donde los elementos opuestos deben estar unidos y a la vez protegidos el uno del otro. Varias de estas historias presentan un encuentro disruptivo entre las entidades opuestas. Aunque este encuentro demuestra ser destructivo no es inequívocamente negativo, ya que el conflicto no es necesariamente un obstáculo a superar o eliminar. Más que trascender la destrucción, la narrativa culmina en un binario irreductible. De esta manera, la yuxtaposición de elementos internos y externos determina tanto al conflicto inicial como al dénouement en estas obras.

Piñera explora las consecuencias del aislamiento total en "La carne”. En esta historia, los habitantes de un pueblo particular están limitados a una dieta restringida a causa de una escasez de carne. De todos modos, uno de los habitantes del pueblo descubre que su propia carne puede servir de sustituta. El resto de la gente empieza a comer de sus propios cuerpos hasta que finalmente se consumen a sí mismos. Irónicamente, la gente del pueblo está más que dispuesta a destruirse ya que la erradicación de sus propios cuerpos no es tan desagradable como la perspectiva de vivir faltos de carne. El doble significado de la 
palabra carne enfatiza además la ironía: los habitantes del pueblo literalmente destruyen su propia carne para no sufrir las consecuencias de verse privados de la carne.

Como en "La isla", la oposición de elementos internos y externos es exagerada a través de la sinécdoque que representa las entidades corporales. El pueblo no debe tan sólo negociar la disrupción del contacto con el mundo exterior, sino que la repentina ausencia de un elemento externo a ser consumido fuerza al cuerpo a ingerir partes de sí mismo como sustituto. Con el uso de esta hipérbole la historia enfatiza la dependencia de lo interno en lo externo. En otras ocasiones Piñera elucida la necesidad de proteger lo interno de una invasión destructiva, pero en "La carne" sugiere que no se puede separar completamente de lo externo. Cuando lo interno se encuentra totalmente necesitado de recursos exteriores la única manera de ser completamente autosuficiente es a través del autoconsumo, recreando la división perdida entre ambos dentro de sí mismo.

Los personajes en "La cara” confrontan un problema parecido: desean una relación que exige intimidad y distanciamiento simultáneamente. El narrador recibe una misteriosa llamada telefónica de un hombre que está desesperado por establecer un contacto prolongado con otra persona. A su vez explica que su cara es tan repulsiva que no es capaz de mantener una relación con nadie que la haya visto. Por lo tanto, ha recurrido a llamar números al azar en búsqueda de interlocutores. Sin embargo, las limitaciones de varias conversaciones con un extraño ha convertido en insatisfactoria esta solución. Ambos personajes intentan sostener contacto sin conocerse personalmente, pero poco después el narrador descubre un deseo irresistible de ver el extraordinario rostro de su nuevo amigo. El narrador resuelve el problema cortándose los dos ojos. No obstante, esta estrategia no se debe ver tan sólo como una repetición de precedentes literarios de auto-castigo, tal como la auto-mutilación de Edipo al final de la obra Edipo rey de Sófocles. El gesto representa, en cambio, una resolución positiva al dilema del personaje:

Una vez que estuve sentado en mi sillón le hice saber que había saltado los ojos para que su cara no separase nuestras almas, y añadí que como ya las tinieblas eran superfluas, bien podrían encenderse las luces. (93)

En esta historia Piñera nuevamente construye una situación en donde ambos personajes deben negociar sus necesidades de contacto y el peligro concomitante de que al fin y al cabo el deseado contacto llegue a separarlos. A través de varias estrategias ellos luchan por resolver el problema manteniendo una unión parcial y controlada. Al final el narrador debe destruir una parte de sí mismo -específicamente, la parte con que percibe el mundo- para poder mantener la relación.

El narrador de "El muñeco" inventa la estrategia de proteger a un cuerpo de las amenazas externas creando otro cuerpo. Para poder proteger al Presidente, el narrador propone la construcción de un maniquí que pueda cumplir con las apariciones públicas del Presidente. La reproducción del Presidente es tan efectiva que los personajes -incluyendo al mismo Presidente-son incapaces de distinguir entre el maniquí y la persona, y al final el muñeco eventualmente reemplaza al Presidente. De esta manera, la reproducción de un cuerpo presenta la oportunidad de resolver el conflicto entre el deseo de proteger el yo corporal de amenazas externas; pero subraya también la necesidad del cuerpo de vencer 
las limitaciones propias de su represión en el otro. Es decir, el cuerpo no puede estar ni completamente aislado ni expuesto, y la posibilidad de una reproducción "falsa” le permite al individuo trascender las limitaciones corpóreas sin interrumpir directamente las fronteras corporales entre lo interno y lo externo. Sin embargo, los resultados del proceso sugieren que la coexistencia de cuerpos putativos externos e internos destruye al individuo a la vez que lo protege ya que lo limita a una existencia sin vida, puramente corporal. Por lo tanto, al igual que en "La carne”, la separación de sí del resto del mundo conduce a la erosión del yo.

En Cuentos fríos, Piñera no sólo explora las dicotomías irreconciliables: como arguye Teresa Cristófani Barreto, a menudo las historias se reducen a la oposición fundamental de dos elementos. ${ }^{4}$ El primer cuento de la colección, "La caída”, se puede leer como un mise en abyme en donde se describe esta estrategia narrativa por medio de su representación dramática. Al igual que los ejemplos discutidos anteriormente, los dos personajes en "La caída” luchan por protegerse a sí mismos de la amenaza de destrucción. Al comenzar la historia ambos personajes están escalando una montaña. Uno de ellos resbala pero, como están atados a una soga, ambos caen. El narrador explica que cada uno está obsesionado con una parte del cuerpo: él con sus ojos y su compañero con la barba. A medida que caen los cuerpos se van borrando más y más, el narrador se ve forzado a decidir entre proteger la apreciada barba del compañero o usar su única mano libre para preservar sus amados ojos. Al final escoge la auto-conservación no sin antes anotar, en las últimas líneas, que la tragedia ha sido prevenida:

Pero no pude hacer lamentaciones pues ya mis ojos llegaban sanos y salvos al césped de la llanura y podían ver, un poco más allá, la hermosa barba gris de mi compañero que resplandecía en toda su gloria. (11)

Esta reducción de los individuos a sus características esenciales se podría ver como la poética del cuento. Es decir, "La caída” representaría un sistema narrativo en donde se eliminan todos los excesos y la escritura se reduce a los aspectos fundamentales. De acuerdo a esta interpretación, la repetida oposición de elementos irreconciliables en los cuentos constituiría parte del sistema. Sin embargo, esta explicación es insuficiente ya que las problemáticas exploradas en los Cuentos fríos también están presentes en la novela $L a$ carne de René. Esta novela, tal vez la obra más frecuentemente leída y estudiada de Piñera, es una larga exploración de los conflictos engendrados por los límites físicos. La novela presenta el dilema constante de un sujeto corpóreo que debe vencer su confinamiento físico y a la vez protegerse de una amenaza de penetración. Más aún, a través de la representación repetida de este conflicto temático Piñera construye una lucha entre fuerzas competitivas de expansión y penetración que se pelean por la carne de René. Tal como en “La isla en peso", el deseo de un aislamiento protectivo en La carne está yuxtapuesto a la

\footnotetext{
${ }^{4}$ En su ensayo sobre Cuentos fríos, Cristófani Barreto examina el estilo minimalista de Piñera por medio de una interpretación de elementos específicos. Establece así una conexión significativa en las imágenes de consumo en "La carne” y el autoconsumo narrativo mediante el cual los textos se reducen a elementos individuales tales como la descripción, la acción o los personajes.
} 
necesidad de fundir lo externo con lo interno. El conflicto entre estas fuerzas irreconciliables se concentra en la superficie que separa el cuerpo del mundo que rodea al texto, René lucha para proteger a su piel de una amenaza de invasión mientras los otros se esfuerzan por trascender este límite. A través de los episodios que muestran esta lucha, la piel de René se convierte en la división que debe ser atravesada o protegida en la batalla por su carne.

Junto a su propia carne, la piel de René a veces constituye el centro y el lugar de negociación. De hecho, en varios episodios la novela enfatiza la supuesta cualidad singular de su piel. René se empeña en proteger su piel de las perforaciones y la penetración. Sin embargo otros personajes están a su vez determinados a llevar a cabo tal penetración. En la primera escena de la novela, la piel de René llama la atención de una vecina, Dalia Pérez. Ella contempla su apariencia y describe la intensa atracción que le inspira esta superficie potencialmente permeable:

Si no posee los músculos del atleta, en cambio en la calidad de su piel reside su belleza. Pero más que esto, lo que lo hace irresistible es la seducción de su cara. En ella la nota dominante que está pidiendo protección contra las furias del mundo. Y cosa extraña: ese aire que pedía protección se manifestaba en su carne de víctima propiciatoria. La señora Pérez la imaginaba herida por un cuchillo o perforada por una bala o pensaba en su uso placentero o doloroso. (15)

En esta descripción lo que incita el deseo es la inherente inestabilidad de los límites corporales de René. Aunque René supuestamente no está al tanto de la reacción de la vecina pronto encuentra una amenaza similar. Más adelante en el capítulo, él ve a su madre curar las heridas que su padre, un carnicero, ha recibido. René siente una obvia repugnancia por estas lesiones, y siente mucha más angustia cuando su padre le avisa que se debe preparar para una suerte similar: "No seré yo quien te hunda el cuchillo en el pecho, hijo mío, pero piensa que en el mundo hay millones de manos y millones de cuchillos” (24).

La penetración vuelve a ser el mecanismo que prefigura el destino de René cuando su padre lo presenta ante "La Causa” y el rol que espera su hijo lleve acabo en su defensa. Justo antes de explicarle la historia de los “chocolatófilos” y la necesidad de René de sacrificar su carne por ellos, el padre le muestra a René una foto del martirio de San Sebastián en la que a la figura del santo perforado se le había sobrepuesto la cara de René. ${ }^{5}$ Una vez más, René está angustiado por la imagen de su piel perforada. Poco después, René es enviado a una academia para ser adoctrinado en un culto al dolor y de esa manera prepararlo para su rol. La escuela se dedica a familiarizar a los estudiantes con el dolor y a cultivar una respuesta apropiada cuando se experimente este. La piel es uno de los focos primarios del entrenamiento. En sus habitaciones cada estudiante encuentra un retrato parecido al que había encargado el padre de René y se les enseña a los estudiantes a emular tal imagen. Al progresar el curso, los directores de la escuela expresan cada vez más preocupación por René quien no está desarrollando una relación apropiada con el sufrimiento carnal. Más aún, la piel de René es identificada como la más absoluta

\footnotetext{
${ }^{5}$ Aunque no se identifica al retrato como la obra de un artista específico, presenta -de acuerdo a la descripción- la clásica imagen del cuerpo de un mártir herido por múltiples flechas.
} 
manifestación de su resistencia. Un colega nota la cualidad pétrea de la piel de René e insiste en que debe ser suavizada para luego poder ser subyugada:

Roger lamió profundamente la frente de René. Movió la cabeza con aire de duda. Pasó la lengua por los labios del rebelde. Volvió a mover la cabeza.

-¿Qué pasa, Roger? -preguntó Cochón.

- Pétrea -se limitó a decir Roger.

Varios de los maestros y estudiantes siguen el ejemplo de Roger y comienzan a lamer el cuerpo de René constantemente en un intento por dominar la resistencia de su superficie.

Se reproduce a René por medio de descripciones plásticas pero también a través de la presencia de dobles. Como los personajes de "El muñeco", los chocolatófilos usan dobles para proteger a su líder. Aunque en La carne estas réplicas no causan confusión entre el original y la copia, René se ve severamente restringido por la presencia de dobles en la novela. Los dobles triunfan al proteger a René como una posible figura pública, pero a su vez lo amenazan y lo limitan como individuo. Al final, René se encuentra continuamente restringido por estas reproducciones de su yo físico.

En varias ocasiones en la novela, uno de los doble se aparece justo cuando René está por escapar de los chocolatófilos y es literalmente detenido por el encuentro. René descubre sus dobles en un ascensor. En una escena intensamente claustrofóbica, el protagonista se descubre encerrado con varios de sus señuelos:

Al abrir la puerta del ascensor empezó el doblaje. Un grupo de cuatro personas -probables vecinos del edificio- entraron conversando animadamente. Eran cuatro seres humanos, pero René los vio como cuatro maniquíes -dobles de su propia persona. (167)

Más tarde, cuando René está determinado a huir de su odiado martirio se encuentra, inesperadamente, con otro doble. Para su pesar, el doble está dispuesto a permanecer con René y, sin saberlo, frustra el escape ya planificado. Por lo tanto, los movimientos físicos de René y su desarrollo personal están delimitados por la presencia de sus múltiples reproducciones. La circunscripción del cuerpo de René mediante la presencia de los dobles se reproduce repetidamente en la novela. En una ocasión queda detenido debido a un impostor que le ha suplantado a su padre. En otra, justo cuando René está a punto de tomar un examen que le aseguraría un futuro lejos de los chocolatófilos, es detenido por otro inesperado encuentro. Paradójicamente, en este caso, la falta de semejanza entre los dos protagonistas engendra el hiato. René no reconoce al hombre como uno de sus dobles pues su apariencia ha sido alterada y ya no se parece más a René. El hombre explica que tuvo una cirugía para liberarse de su vida como señuelo pero necesita que René testifique su estado como irreconocible para poder finalizar su destitución de la ocupación. ${ }^{6}$

${ }^{6}$ El encuentro claramente revela que tanto el protagonista como sus dobles están restringidos por una relación. Por una parte, el encuentro de René con su doble le evita, nuevamente, un posible distanciamiento de "La Causa”. Por otra parte, la situación del doble enfatiza la fuerza gravitacional experimentada por los duplicados. Sobre todo, de acuerdo al álter ego, para convertirse en uno de los dobles de René no hacía falta ninguna cirugía. Sin embargo, para librarse de la tarea su cara tuvo 
Aparte de las reproducciones plásticas y vivientes, René también se encuentra con una imitación inanimada de su cuerpo. Luego de pasar la noche en la casa de Dalia, descubre, flotando en la bañera, un maniquí que se le asemeja. La vecina explica que adquirió el maniquí para satisfacer su deseo por la carne de René, pero que se había sentido insatisfecha con la imitación. Al igual que los chocolatófilos y Ramón, ella ha usado una reproducción para manipular a René y satisfacer su deseo carnal por él. René siente repugnancia por el maniquí, pero reacciona más a la apariencia de la piel en la réplica que a su existencia o al uso que le da Dalia. Comenta sobre la extraña, suave cualidad de la piel sumergida: "Su carne parecía blanda y hasta fofa, por efecto de la hinchazón, seguramente" (161). Irónicamente, parece que Dalia ha logrado con la piel del maniquí lo que les fue imposible a los compañeros de escuela de René: a través de la creación de este doble, Dalia fue capaz de aproximarse a la deseada subyugación de la carne de René.

Los dobles determinan el futuro de René y también restringen su movimiento. Por medio de sus intervenciones, sistemáticamente se evita que René se mueva más allá de una limitada área geográfica. La libertad de su padre y de su planificado martirio requiere que se distancie físicamente de esos elementos. Sin embargo, él es continuamente echado atrás, hacia el epicentro de las fuerzas que lo contienen. El constante refuerzo a la represión de René hace que su destino parezca cada vez más inevitable. En un momento dado, René se encuentra a sí mismo en la calle enfrente del mismo edificio del cual había intentado huir, los cuarteles generales de La Causa. El deseo de René por escapar es frustrado en repetidas ocasiones por su encerramiento en espacios controlados por dicha organización.

Junto a la manipulación física y al encerramiento, también se usa el lenguaje para controlar a René. Durante la primera clase, cada alumno de la escuela recibe un bozal. De acuerdo a René, la restricción está diseñada para mejorar la experiencia del dolor y, de tal manera, facilitar su educación: "De pronto, recordó la expresión del señor Mármolo: 'Sufrir en silencio...' Era evidente que el bozal impediría el sufrimiento clamoroso, pregonado, a gritos” (76-77). A través de esta restricción los maestros fuerzan a los alumnos a experimentar el dolor exclusivamente en términos de la carne. Esta técnica sugiere que la inhabilidad de articular la experiencia del dolor físico aumenta la intensidad y la pureza de la experiencia misma.

Junto a las restricciones de la expresión oral, las técnicas pedagógicas en la escuela también fomentan una relación específica con el lenguaje escrito. Después de ponerse el bozal, los estudiantes van a un salón lleno de sillas eléctricas. En este salón son torturados con una serie de descargas que van aumentando de voltaje. Sin embargo, parece ser que el tan sólo recibir las descargas no es suficiente. El instructor, a su vez, administra la corriente eléctrica durante la lectura de un texto. No obstante, el profesor de la clase de René queda muy desconcertado cuando el sistema falla y no le administra la corriente eléctrica a los estudiantes:

que ser perforada y alterada con instrumentos médicos para poder romper los lazos entre ambos personajes. Además, este proceso solo no es suficiente: René debe dar fe de la ausencia de cualquier parecido entre él y la cara alterada del otro antes de que el hombre pueda se liberado definitivamente de su obligación. 
No pudo continuar [el profesor]. La voz se le había rajado en la garganta y allí se quedó como un cadáver. El dedo se movía histéricamente sobre el botón, amenazando desarraigarlo... Una risa amordazada, pero no menos burlona, se clavaba en la dignidad del profesor, haciéndole perder toda compostura. (90-1)

El episodio demuestra que la manipulación de la respuesta estudiantil al texto es un aspecto importante en la educación, y que el no poder controlarla efectivamente constituye una grave amenaza al poder de los instructores.

El uso del lenguaje escrito para controlar la carne de René no se limita a su educación formal. Después de abandonar la escuela, la escritura sigue teniendo un rol importante en la represión. Hay dos ocasiones en la novela en las que René recibe un mensaje escrito en un pedazo de papel. El primero es de Ramón, que confirma su muerte y le sugiere a René que siga su ejemplo: ““Espero que tu carne tenga el final de la mía’. Ramón” (184). En la segunda instancia René tiene miedo del contenido del mensaje y el efecto que pueda tener en él. Inicialmente se rehusa a leerlo, pero al final la curiosidad lo vence. Su temor prueba estar bien fundamentado ya que el contenido del mensaje le impide tomar un examen ya previsto. En ambos casos, la posibilidad de escape de René es truncada al recibir un papel escrito.

Aunque la escritura triunfa en refrenar a René, también posee el poder de liberación. René está ansioso de tomar y pasar su examen porque él cree que le ofrece un futuro sin amenazas para su carne: una carrera en taquigrafía y mecanografía. Además, se espera que él haga un buen examen pues ya había demostrado grandes habilidades en ambas áreas. En otras palabras, la habilidad de René de producir y manipular la palabra escrita mecánicamente le ofrece una posible fuga de la existencia carnal que lo atemoriza. El escape, sin embargo, es frustrado por el encuentro con el doble mencionado anteriormente. Es significativo que este hombre no sólo necesita que René testifique su transformación, sino que también debe obtener su firma para poder ser relevado definitivamente de su función como doble. Al principio, René duda en firmar: "No, no firmaría nada; con su firma no iba a acceder a las siniestras maquinaciones de los servidores de la carne” (193). Es decir, él le teme al peligro potencial de renunciar a su poderosa inscripción. Pero, una vez que lee el documento y descubre que este hombre en verdad quiere que de fe por escrito de lo que ya él había confirmado visualmente-que no pudo reconocer a su doble-entonces firma el papel. De hecho, la firma de René demuestra ser poderosa porque es ese el documento que liberará al hombre de su estricto rol de doble. Por ende, el lenguaje mismo constituye un límite disputado en La carne. Aún cuando la carne ha sido exitosamente dominada, el lenguaje -presumiblemente- tiene el poder de limitar o hasta llegar a subvertir este control sobre la carne. De esta manera, tanto la generación como la recepción de la escritura debe ser cuidadosamente controlada para así poder regular completamente la represión.

Al final, en los textos de Piñera, la subjetividad es determinada por la negociación constante de los límites. Los personajes se definen por medio de las luchas para preservar o alterar los límites que los circunscriben. En Feminine Sexuality, Lacán argumenta que el sujeto está construido por una búsqueda perpetua de un otro inasequible. En el caso de La carne, el sujeto no busca un otro encarnado, pero sí lucha contra unas construcciones 
alternativas de su yo. Es decir, en la obra de Piñera, el límite que define al sujeto no se construye entre un yo físico y el otro. La dinámica se articula, en cambio, en términos de la contención de una entidad específica y su relación con los elementos externos que la rodean. Visto de esta manera, además, la dinámica de la dicotomía en la obra de Piñera apunta a un sistema de género sexuado. A más de engendrar una operación dialéctica que forma parte de las tradiciones metafísicas occidentales, las oposiciones binarias en la narrativa y la poesía del autor se vinculan claramente con la carne, el cuerpo, el deseo y la sexualidad. Articulan, pues, una resistencia ante cualquier sistema normativo que demarca los límites de la carne y que define el deseo de acuerdo con estos límites absolutos y universales.

Tanto en los textos de Piñera como en las obras de Mendieta, el cuerpo se encuentra posicionado ante el locus tradicional de la heteronormatividad. Dichos cuerpos constituyen así el signo elusivo que se resiste frente a los procesos de significación engendrados por los modos discursivos hegemónicos. La sexualidad apunta a una visión alternativa en la cual el cuerpo queda inevitablemente desplazado o atrapado. En el caso de Piñera en particular, la imposibilidad que subraya está íntimamente vinculada con la convergencia del espacio de la isla y la construcción normativa de la nación. Como bien argumentan David Eng y David Kazanjian en su análisis de las culturas asiáticas, la sexualidad queer tiende a construirse en el exilio, lejos de las restricciones de la familia y la infraestructura de la nación, y -por ende- está inexorablemente asociada con la experiencia de la pérdida y el duelo. La obra de Piñera y las lecturas críticas de ésta que hemos examinado en el presente ensayo, sin embargo, no apuntan a los procesos de desplazamiento geográfico y enajenación que pueden resultar del exilio, la transmigración o la globalización. Articulan más bien una negociación del desencuentro que produce las configuraciones del espacio de la isla-nación y que, a su vez, establecen una dicotomía absoluta entre la normatividad interior y las subjetividades aberrantes exteriorizadas. De este modo, los textos de Piñera presentan una dinámica discursiva que puede equipararse a la construcción del espacio fuera del museo producido por la posicionalidad de Mendieta.?

Dadas las diversas construcciones de los “cuerpos" asediados-individuales, colectivos e insulares- en la escritura de Piñera, la lucha entre el interior y el exterior genera la subjetividad. Esto es, la yuxtaposición de fuerzas opuestas que ofrece, respectivamente, la protección o la expansión, se articula en términos de los límites de un cuerpo individual de manera tal que tanto la identidad nacional como la subjetividad se construyen a través de un conflicto sostenido entre lo interno y lo externo. Asimismo, más allá de las interrogantes políticas y sexuales, Piñera construye una poética de resistencia corporal que

\footnotetext{
7 Se le podría atribuir a esta posicionalidad también la creciente atención que han recibido obras piñerianas en los últimos años y la enorme popularidad de éstas. Además de las representaciones teatrales de la obra del autor en sí (Quiroga, Tropics 121 n.42), en el 2001 Tania Bruguera montó un performance inspirado por la poesía de Piñera y Teatro El Público presentó, "María Antonieta o la maldita circunstancia del agua por todas partes”, una obra que incorporaba varios textos del autor. En ambos casos, la reterritorialización de los textos piñerianos reafirma la importancia retórica de la insularidad en el discurso cultural pos-revolucionario. Más aún, forman parte significativa de una visión de desgaste o imposibilidad, apuntan a la necesidad de trascender los límites tradicionales y contribuye así al proyecto de los artistas cubanos contemporáneos.
} 
cuestiona, sin dar tregua, los límites y las limitaciones de los sistemas de conocimiento y poder.

\section{BiBLIOGRAFÍA}

Bejel, Emilio. Gay Cuban Nation. Chicago/London: University of Chicago Press, 2001. Bruguera, Tania. “La Isla en Peso.” Performance. Galería Latinoamericana, Casa de las Américas, La Habana. 8 sept 2001.

Cabrera Infante, Guillermo. “The Death of Virgilio”. Cold Tales. Hygiene, CO: Eridanos Press, 1988. 11-14.

Mea Cuba. Barcelona: Plaza \& Janés, 1993.

Cristófani Barreto, Teresa. “Los cuentos fríos de Virgilio Piñera”. Hispamérica 24/71 (1995): 23-33.

Eng, David y David Kazanjian. “Introduction: Mourning Remains”. Loss. Berkeley: University of California Press, 2003.

García Chichester, Ana. "Superando el caos: estado actual de la crítica sobre la narrativa de Virgilio Piñera”. Revista Interamericana de Bibliografía/Inter-American Review of Bibliography 42/1 (1992): 132-147.

Hernández, Eloy J. “Coco Fusco”. New Art Examiner 25 (1997): 62-3

Lacan, Jacques. Feminine Sexuality. Jacqueline Rose, trad. New York/London: W.W. Norton \& Company and Pantheon Books, 1982.

Mauvaise conduite: Improper Conduct. Néstor Almendros y Orlando Jiménez-leal (dirs.) New York: Cinevista, Losange, Société nationale de télévision en couleur “Antenne 2”, 1984.

Piñera, Virgilio. “La isla en peso”. Poesía y prosa. La Habana: Espuela de Plata, 1944. Cuentos fríos. Buenos Aires: Editorial Losada, 1956.

Teatro completo. La Habana,: Ediciones R, 1960.

La carne de René. Madrid: Ediciones Alfaguara, 1985.

Cold Tales. Hygiene, CO: Eridanos Press, 1988.

Quiroga, José. “On the Weight of the Insular Flesh”. Hispanisms and Homosexualities. Sylvia Molloy y Robert Irwin, eds. Durham: Duke University Press, 1998.

Tropics of Desire: Interventions from Queer Latino America. New York/London: New York University Press, 2000.

Teatro El Público. "María Antonieta o la maldita circunstancia del agua por todas partes". Obra teatral. Teatro Trianon, La Habana. 23 sept 2001.

Tully, Judd. “Carl \& Ana: Ten Years + One After”. New Art Examiner 26 (1999): 70. West, Alán. Tropics of History: Cuba Imagined. Westport, CT: Bergin \& Garvey, 1997. 